\title{
A randomized, multicenter, controlled study, comparing efficacy and safety of a new complementary and alternative medicine (CAM) versus Solifenacin Succinate in women with overactive bladder syndrome
}

\author{
Carlo Vecchioli-Scaldazza ${ }^{1}$, Carolina Morosetti ${ }^{2}$, Serena Maruccia ${ }^{3}$, Stefano Casellato ${ }^{3}$, \\ Wilma Rociola ${ }^{4}$, Ester Illiano ${ }^{5}$, Francesco Garofalo ${ }^{6}$ \\ ${ }^{1}$ Uroginecology Unit, ASUR n ${ }^{\circ} 2$ Jesi (AN), Italy; \\ ${ }^{2}$ Clinical Laboratory Department, ASUR n ${ }^{\circ} 2$ Jesi (AN), Italy; \\ ${ }^{3}$ Functional Urology Unit, Zucchi Clinical Institutes, Monza, Italy; \\ ${ }^{4}$ Urology Unit, ASL1, Umbria, Italy; \\ ${ }^{5}$ Department of Surgical and Biomedical Sciences, Urology and Andrology Clinic, University of Perugia, Italy; \\ ${ }^{6}$ Urology Division, Villa Maria Hospital, Rimini, Italy.
}

\begin{abstract}
Summary Introduction: To assess efficacy and tolerability of a new complementary and alternative medicine (CAM) consisting of vitamins (C and D), herbal products (cucurbita maxima, capsicum annum, polygonum capsicatum) and amino acid L-Glutammina, in the treatment of female Overactive Bladder syndrome (OAB).

Materials and methods: 90 consecutive women with $O A B$ symptoms were enrolled in this prospective, randomized, controlled study. Women were divided randomly into two groups of 45 patients each. In group A, women received Solifenacin Succinate (SS), 5 mg. once a day for 12 weeks. In group B, women received CAM, $930 \mathrm{mg}$, twice daily for 12 weeks. Women were assessed with 3-day micturition diary, Patient Perception of Intensity of Urgency Scale (PPIUS), Overactive Bladder questionnaire Short Form (OAB-q SF) and Patient Global Impression of Improvement questionnaire (PGI-I). Results: 8 patients in group $A$ and 1 patient in group $B$ dropped out from therapy because of side effects. A reduction in the number of daily micturitions, nocturia and episodes of urge incontinence was present with both SS and CAM with statistically highly significant differences, but CAM was significantly more effective than SS. PPIUS and OAB-q SF showed improvements with both SS and CAM with a more significant efficacy of CAM. PGI-I, demonstrated improvements in the two groups of patients with a greater satisfaction expressed by patients treated with CAM.

Conclusions: the small number of patients does not permit definitive conclusions; however, the results of the research showed the greater effectiveness and tolerability of CAM.
\end{abstract}

KEY WORDS: Overactive bladder; Solifenacin; Capsaicin; Cucurbita maxima; Capsicum annum; Polygonum cuspidatum; Vitamin D; Vitamin C; Glutamine; Complementary medicine.

Submitted 25 September 2017; Accepted 3 November 2017

\section{INTRODUCTION}

Overactive bladder syndrome (OAB) is a chronic disease characterized by urinary urgency with or without urge incontinence, frequency and nocturia (1) with huge eco- nomic burdens and detrimental effects on the quality of life of patients (2). The prevalence of OAB in women increases with age and is present in approximately 30\% of women over the age of 65 years (3) and in the general population it is estimated at $11.8 \%$ (4). Conservative treatment is considered the first line treatment in these patients, but when this therapeutic option is ineffective, antimuscarinic agents represent the therapy of choice. Although a long-lasting therapy is required to obtain better control of symptoms, a high percentage of patients undergoing these drugs, discontinue the treatment after a few months especially for side effects (5-6). After failure of a single drug, most practitioners try a different pharmacological treatment and if this second option also fails, more invasive options are considered (7). Recently a complementary and alternative medicine (CAM) called Kubiker (Naturmed, Montegranaro, FM, Italy), consisting of vitamins (C and D), herbal products (cucurbita maxima, capsicum annum, polygonum capsicatum) and amino acid L-Glutammina, has been proposed in the treatment of $O A B$. To assess its efficacy and its tolerability, we performed a randomized, controlled, multicenter study comparing CAM with Solifenacin Succinate, a well-known drug used in the treatment of OAB.

\section{MATERIAL AND METHODS}

From January 2016 to January 2017, 90 consecutive women (mean age 65 years; range 40-75) with symptoms of overactive bladder (urgency, urinary frequency, with or without urge incontinence) were enrolled in this open label, prospective, randomized, controlled study. Women were divided randomly into two groups of 45 patients each using online randomization (Graph Pad Quick Calcs software: http://www. graphad.com/quickcalcs/ randomize1) by an independent biostatistician who was unaware of treatments performed by patients and was not involved in the study. In group A, women received Solifenacin Succinate 
(SS), $5 \mathrm{mg}$. once a day for 12 weeks. In group B, women received CAM, $930 \mathrm{mg}$, twice daily for 12 weeks. Patients with urinary tract infection, neurological disease, bladder lithiasis, genital prolapse higher than stage II on POP-Q system, uncontrolled narrow angle glaucoma, pelvic tumours, post void residual urine $\geq 100 \mathrm{ml}$, previously treated with radiation therapy, antimuscarinic agents, antidepressants and antianxiety agents, were excluded.

\section{Endpoints}

Improvements in $\mathrm{OAB}$ symptoms, including reduction in number of voids per $24 \mathrm{~h}$, night time frequency, urgency and urge incontinence were considered the primary efficacy end point. The impact of OAB symptoms on patients' quality of life (QoL) and the patient impression of improvement were considered the secondary end point. Number of voids per $24 \mathrm{~h}$, episodes of nocturia and urge incontinence were evaluated using a 3-day micturition diary. Urgency was assessed by the Patient Perception of Intensity of Urgency Scale (PPIUS) represented by a 5-point scale from 0 (no urgency) to 4 (urge incontinence).

The secondary end point was assessed with the Overactive Bladder questionnaire Short Form (OAB-q SF). The questionnaire consists of 6 items related to symptoms with 6 possible options ranging from "not at all" (score 1) to "a very great deal" (score 6), and a healthrelated quality of life scale with 13 items, with 6 response options ranging from "none of the time" (score 1) to "all of the time" (score 6).

Improvement was evaluated with the Patient Global Impression of Improvement questionnaire (PGI-I). The PGII is a validated generic tool for assessment of the overall improvement or deterioration that patients experience following the treatment. It is a 7-point scale from "very much improved" (score 1), to "very much worse" (score 7). The micturition diary, OAB-q SF and PPIUS were completed before and after each treatment. PGI-I was performed only at the end of each treatment.

The study was conducted in accordance with the ethical principles of the Declaration of Helsinki and the protocol was approved by the local ethics committee.

All patients signed informed consent before starting treatment. The results were assessed by a researcher blinded to treatment performed by patients.

\section{Statistical analysis}

Statistical analysis was performed using MedCalc software (version 12.7.7). Data in each group was assessed by D'Agostino-Pearson test. After having checked the normal distribution, data was processed using parametric tests: paired sample $t$ test or independent sample $t$ test. If normality was rejected, data was processed using non parametric tests: Wilcoxon test for paired sample and MannWhitney for independent sample. Data was expressed as means \pm SD. A p value $<0.05$ was considered significant.

\section{RESULTS}

Of the 50 women initially enrolled in each group, 8 patients in group A suspended therapy because of side effects (dry mouth, constipation), and 1 patient in group $\mathrm{B}$ because of allergic reaction. In addition one patient in group B was not evaluable because of incorrect compilation of questionnaires. Thus, 42 women in group $\mathrm{A}$ (mean age: 66 years, range 42-73) and 48 women in group B (mean age: 64 years, range 40-75) were evaluable for the study. A reduction in the number of daily micturitions was present both with SS and with CAM with statistically highly significant differences, but CAM was significantly more effective than SS (Table 1).

A reduction of night micturition was found in group A and in group B with a highly significant statistical difference but CAM was statistically more effective than SS. Episodes of urge incontinence decreased with highly significant statistical differences in group A and B with more efficacy in the group treated with CAM.

Improvements with highly significant statistical differences were found in the PPIUS in both SS and CAM groups. However CAM demonstrated more efficacy than SS with a significant difference. The quality of life of patients evaluated with the OAB-q SF, showed highly significant improvements in both SS and CAM groups (Table 2). However CAM was significantly more effective in both items related to symptoms quality of life (Table 2). Patients' evaluation of the two different treatments performed at the end of the study assessed with PGI-I, demonstrated improvements in the two groups of patients with a greater satisfaction expressed by patients treated with CAM (Table 2).

\section{Table 1.}

OAB symptoms assessed with 3-day micturition diary in patients treated with Solifenacin Succinate (SS) or CAM.

\begin{tabular}{|c|c|c|c|c|c|c|}
\hline $\begin{array}{l}\text { 3-day } \\
\text { micturition diary }\end{array}$ & \multicolumn{3}{|c|}{$\begin{array}{c}\text { SS }\left(n^{\circ} 42\right) \\
\text { (Mean age } 66 ; 42-73)\end{array}$} & \multicolumn{3}{|c|}{$\begin{array}{c}\text { CAM }\left(n^{\circ} 48\right) \\
\text { (Mean age } 64 ; 40-75)\end{array}$} \\
\hline Daily micturition & $\begin{array}{c}\text { before } \\
11.6 \pm 1.2 \\
\text { SS }\end{array}$ & $\begin{array}{c}\text { after } \\
10.2 \pm 1.96 \\
\text { after }\end{array}$ & $\begin{array}{c}\text { p value } \\
<0.0001 * \\
\text { vs }\end{array}$ & $\begin{array}{c}\text { before } \\
11.26 \pm 1.02 \\
\text { CAM }\end{array}$ & $\begin{array}{c}\text { after } \\
9.00 \pm 1.62 \\
\text { after }\end{array}$ & $\begin{array}{c}p \text { value } \\
<0.0001 * * * \\
0.0046 * * * *\end{array}$ \\
\hline Nocturia & $\begin{array}{c}\text { before } \\
2.7 \pm 1.14 \\
\text { SS }\end{array}$ & $\begin{array}{c}\text { after } \\
2.15 \pm 1.42 \\
\text { after }\end{array}$ & $\begin{array}{c}\text { p value } \\
0.0003^{*} \\
\text { vs }\end{array}$ & $\begin{array}{c}\text { before } \\
2.4 \pm 0.94 \\
\text { CAM }\end{array}$ & $\begin{array}{c}\text { after } \\
1.45 \pm 1.01 \\
\text { after }\end{array}$ & $\begin{array}{c}\text { p value } \\
<0,0001 * * * \\
0,0240 * * * *\end{array}$ \\
\hline Urge incontinence & $\begin{array}{c}\text { before } \\
3.5 \pm 1.2 \\
\text { sS }\end{array}$ & $\begin{array}{c}\text { after } \\
2.55 \pm 1.56 \\
\text { after }\end{array}$ & $\begin{array}{c}\text { p value } \\
<0.0001 * * * \\
\text { vs }\end{array}$ & $\begin{array}{c}\text { before } \\
3.17 \pm 0.93 \\
\text { CAM }\end{array}$ & $\begin{array}{c}\text { after } \\
1.89 \pm 1.13 \\
\text { after }\end{array}$ & $\begin{array}{c}p \text { value } \\
<0.0001 * * * \\
0.036 * *\end{array}$ \\
\hline
\end{tabular}

*Paired samples t-test; **Independent samples t-test; $* \star *$ Wilcoxon test for paired samples;

$* * *$ Mann-Whitney test (Independent samples). 
Table 2.

Improvements assessed with Quality of Life questionnaire Short Form (OAB-q SF 6 and 13), Patient Perception of Intensity of Urgency Scale (PPIUS) and Patient Global Impression of Improvement questionnaire (PGI-I) in patients treated with Solifenacin Succinate (SS) or CAM.

\begin{tabular}{|c|c|c|c|c|c|c|}
\hline Questionnaires & \multicolumn{3}{|c|}{$\begin{array}{c}\text { SS }\left(n^{\circ} 42\right) \\
\text { (Mean age } 66 ; 42-73 \text { ) }\end{array}$} & \multicolumn{3}{|c|}{$\begin{array}{c}\text { CAM }\left(n^{\circ} 48\right) \\
\text { (Mean age } 64 ; 40-75)\end{array}$} \\
\hline OAB-q SF 6 & $\begin{array}{c}\text { before } \\
26.05 \pm 4.04 \\
\text { SS }\end{array}$ & $\begin{array}{c}\text { after } \\
20.55 \pm 7.05 \\
\text { after }\end{array}$ & $\begin{array}{c}p \text { value } \\
<0.0001 * \\
\text { vs }\end{array}$ & $\begin{array}{c}\text { before } \\
24.36 \pm 5.92 \\
\text { CAM }\end{array}$ & $\begin{array}{c}\text { after } \\
18.94 \pm 5.51 \\
\text { after }\end{array}$ & $\begin{aligned} & p \text { value } \\
< & 0.0001 * \\
< & 0.001 * *\end{aligned}$ \\
\hline OAB-q SF 13 & $\begin{array}{c}\text { before } \\
55.35 \pm 9.94 \\
\text { SS }\end{array}$ & $\begin{array}{c}\text { after } \\
44.88 \pm 13.13 \\
\text { after }\end{array}$ & $\begin{array}{c}p \text { value } \\
<0.0001^{*} \\
\text { vs }\end{array}$ & $\begin{array}{c}\text { before } \\
51.81 \pm 7.17 \\
\text { CAM }\end{array}$ & $\begin{array}{c}\text { after } \\
38.17 \pm 7.29 \\
\text { after }\end{array}$ & $\begin{array}{c}p \text { value } \\
<0.0001 * \\
0.0062 * *\end{array}$ \\
\hline PPIUS & $\begin{array}{c}\text { before } \\
3.55 \pm 0.8 \\
\text { SS }\end{array}$ & $\begin{array}{c}\text { after } \\
2.65 \pm 1.19 \\
\text { after }\end{array}$ & $\begin{array}{c}p \text { value } \\
<0.0001 * * * \\
\text { vs }\end{array}$ & $\begin{array}{c}\text { before } \\
3.47 \pm 0.71 \\
\text { CAM }\end{array}$ & $\begin{array}{c}\text { after } \\
1.94 \pm 0.98 \\
\text { after }\end{array}$ & $\begin{array}{c}p \text { value } \\
<0.0001 * * * \\
0.0039 * * * *\end{array}$ \\
\hline$\overline{\mathrm{PGI}-\mathrm{I}}$ & & $\begin{array}{c}2.75 \pm 0.99 \\
\text { SS }\end{array}$ & vs & CAM & $2.32 \pm 0.72$ & $0.0393 * * * *$ \\
\hline
\end{tabular}

\section{Discussion}

Complementary and Alternative Medicine (CAM) includes various practices, measures and products which are not presently considered to be a part of conventional medicine such as herbal products, vitamins, minerals and amino acids (8). "Complementary medicine" does not propose as an alternative to conventional treatment, but rather a supplement to another treatment, while the term "alternative" medicine is also used as a real alternative to conventional medicine $(8,9)$. More than a third of the population of the United States (US) of America uses some form of CAM and different urological conditions and diseases are treated with CAM (e.g. LUTS/BPH, cancer, prostatitis, urinary tract infection, urolithiasis, infertility and erectile dysfunction) (8). A 2002 survey of US adults aged $\geq 18$ years conducted by the Centers for Disease Control and Prevention, indicated that $74.6 \%$ of those with $\mathrm{OAB}$ had used some form of CAM and that women were more likely than men to use these treatments (10). CAM used in this study, consists of two different vitamins ( $C$ and $D$ ), three different herbal products (cucurbita maxima, capsicum annum, polygonum capsicatum) and the amino acid L-Glutammina.

Many studies have been carried out in this regard.

Maserejian et al. in a cross-sectional analysis performed on intakes of vitamins and minerals in relation to urinary complaints in women, found that women who had highdose intake of vitamin C supplements were more likely to report storage symptoms of frequency and urgency, whereas vitamin $\mathrm{C}$ from food and beverages were inversely associated with voiding symptoms (11). Highly acidic urine, such as that which could result from highdose vitamin C (12), could plausibly affect the urothelium and contribute to lower urinary tract symptoms (LUTS) (11). A study of the effects of urinary $\mathrm{pH}$ on bladder sensitivity in asymptomatic women found that increased urine acidity leads to increased micturition desire (13). Ascorbic acid has also been found to activate mast cells, which are present in the urothelium, thereby possibly contributing to LUTS $(14,15)$. Therefore vitamin C may contribute to LUTS in dose-dependent and symptom-specific ways and for some women, $\mathrm{OAB}$ symptoms of frequency and urgency could be ameliorated by the right intake of vitamin C (11). Vitamin D has proven to be effective in the treatment of urinary incontinence $(16,17)$ and its deficiency has been associated with moderate-severe urinary incontinence and with the presence of $\operatorname{LUTS}(18,19)$. A cross-sectional analysis performed using 2005-2006 National Health and Nutrition Examination Survey data about vitamin D and pelvic floor disorders in women, demonstrated how higher vitamin D levels were associated with decreased risk of pelvic floor disorders (20). Similar efficacy has been found in vitamin $\mathrm{D}$ analogous (elocalcitol) in the therapy of overactive bladder (21). Many studies have been performed on Cucurbita pepo and Cucurbita maxima. The pumpkin seed oil obtained from Cucurbita pepo and Cucurbita maxima has been proven to be effective in the treatment of OAB symptoms with a significant reduction of the symptoms assessed with Overactive Bladder Symptoms Score questionnaire (22). Furthermore, Cucurbita pepo has been effective in improving symptoms and quality of life of patients with BPH (23). Polygonum cuspidatum has been broadly utilized as a herbal medicine and its components have shown antioxidants activity (24). Capsaicin, a chemical used in the therapy of $\mathrm{OAB}$ syndrome, is present in the fruit of most species of capsicum. Capsaicin was the first vanilloid to be used for therapeutic purposes and many studies have been performed on its use in the treatment of LUTS (25). Its intravesical use was effective but its clinical development for treatment of lower urinary tract diseases has been abandoned due to adverse events, reported by $>50 \%$ of patients (pelvic pain, facial flush, worsening of incontinence, autonomic dysreflexia, urinary tract infection and haematuria) (25). For this reason there was a preference for the use of resiniferatoxin, a capsaicin analogue, especially for the treatment of intractable LUTS, particularly those associated with neurogenic detrusor overactivity or idiopathic detrusor overactivity. (26). These two neurotoxins act by desensitizing the transient receptor potential vanilloid type 1 (TRPV1), a non-specific $\mathrm{Ca}^{2+}$ channel pre- 
viously known as vanilloid receptor (27). We did not find studies on the use of Glutamine in patients with LUTS. However, even if Glutamine is the most abundant amino acid in the bloodstream of mammals and it is classified as a non-essential amino acid, in certain circumstances it may become an essential nutrient (28) as a nutritional supplements in critically ill patients (29).

It has an important role in the maintenance of intestinal structure and functions and supplementation with glutamine has proved to be beneficial to the immunological system functions; it improves nitrogen balance and nutritional parameters in the post-operative period and lessens protein loss in severe catabolic states (30).

Glutamine stimulates synthesis and inhibits the degradation of proteins, it stimulates the synthesis of hepatic glycogen and is an energy source for cell division, for the growth of different cells of rapid replication, such enterocytes, colonocytes and fibroblasts as well as for other cells of the immune system (28). An analysis of the data relating to every constituent component of CAM used in this study, appears to confirm that the majority of these components are effective in the treatment of LUTS. However, in literature there is no product with the same characteristics as this CAM. Furthermore, the moderate number of patients enrolled in this study, represents a bias that prevents us from drawing definitive conclusions. However the reduction in the number of daily micturitions and episodes of urge incontinence and the improvement in the quality of life in women treated with CAM compared to SS, must be underlined, as well as the great adherence to the therapy. Patients' adherence to the therapy represent an important aspect of $\mathrm{OAB}$ treatment. Many studies have shown a high percentage of patients discontinuing therapy prematurely: poor efficacy, side effects (dry mouth, constipation, dry eyes, blurred vision, cognitive impairment) and costs were the most important causes $(5,6)$.

In this study, CAM showed a great tolerability with a greater adherence and persistence of patients to therapy with only one woman suspended treatment for allergic reaction.

\section{Conclusions}

In this study, this new complementary and alternative medicine recently proposed in the therapy of OAB syndrome, was an effective and well tolerated treatment. However, the small number of patients prevent us from drawing definitive conclusions. Further studies on a greater number of patients are needed to confirm these findings.

\section{REFERENCES}

1. Abrams P, Cardozo L, Fall M, et al. The standardisation of terminology of lower urinary tract function: report from the standardisation sub-committee of the international continence society. Neurourol Urodyn. 2002; 21:167-178.

2. Irwin DE, Milsom I, Hunskaar S, et al. Population-based survey of urinary incontinence, overactive bladder, and other lower urinary tract symptoms in five countries: results of EPIC study. Eur Urol. 2006; 50:1306-1314.
3. Stewart WF, Van Rooyen JB, Cundiff GW, et al. Prevalence and burden of overactive bladder in the United States. World J Urol. 2003; 20:327-336.

4. Irwin DE, Abrams P, Milsom I, et al. Understanding the elements of overactive bladder: questions raised by the EPIC study. BJU Int. 2008; 101:1381-1387.

5. Anderson KE, Chapple CR, Cardozo L, et al. Pharmacological treatment of overactive bladder: report from the international consultation on incontinence. Curr Opin Urol. 2009; 19:380:394.

6. Yu YF, Nichol MB, Yu AP, Ahn J. Persistence and adherence of medications for chronic overactive bladder/urinary incontinence in the California Medical Program. Value Health. 2005; 4:495-505.

7. Bolduc S, Katherine M, Lebel S, et al. Double anticholinergic therapy for refractory overactive bladder. J Urol. 2009; 182:2033-2039.

8. Dreikorn K. Complementary and alternative medicine in urology.BJU International. 2005; 96:1177-1184.

9. Cohen MH. Complementary and integrative medical therapies, the FDA, and the NIH: definitions and regulation. Dermatologic Therapy. 2003; 16:77-84.

10. Chughtai B, Kavaler E, Lee R, et al. Use of herbal supplements for overactive bladder. Rev Urol. 2013; 15:93-96.

11. Maserejian NN, Giovannucci EL, McVary KT, McKinlay JB. Intakes of vitamins and minerals in relation to urinary incontinence, voiding, and storage symptoms in women: A cross-sectional analysis from the Boston area community Health Survey. Eur Urol. 2011; 59:1039-1047.

12. Axelrod DR. Ascorbic acid and urinary pH. JAMA. 1985; 254:1310-1311.

13. Lavin JM, Hosker GL, Smith AR. Does urinary $\mathrm{pH}$ influence micturition desire? Neurourol Urodin. 1997; 16:396-397.

14. Batler RA, Sengupta S, Forrestal SG, et al. Mast cell activation triggers a urothelial inflammatory response mediated by tumornecrosis factor-alpha. J Urol. 2002; 168:819-825.

15. Dillon PF, Root-Bernstein RS, Lieder CM. Ascorbate enhancement of $\mathrm{H} 1$ histamine receptor sensitivity coincides with ascorbate oxidation inhibition by histamine receptors. Am J Physiol Cell Physiol. 2006; 291:C977-984.

16. Oberg J, Verelst $M$, Jorde $R$, et al. High dose vitamin D may improve lower urinary tract symptoms in postmenopausal women. J steroid Biochem Mol Biol. 2017; pii:S0960-0760(17)30078-X.

17. Gau JT. Urinary incontinence resolved after adequate vitamin $D$ supplementation: a report of two cases. J Am Geriatric Soc. 2010; 58:2438-2439.

18. Vaughan CP, Johnson TM, Goode PS, et al. Vitamin D and lower urinary tract symptoms among men: results from the 20052006 National Health and Nutrition Examination Survey. Urology. 2011; 78:1292-1297.

19. Elshazly MA, Sultan MF, Aboutaleb HA, et al. Vitamin D defiency and lower urinary tract symptoms in males above 50 years of age. Urol Ann. 2017; 9:170-173.

20. Badalian SS, Rosenbaum PF. Vitamin D and pelvic floor disorders in women: results from the National mHealth and Nutrition Examination Survet. Obstet Gynecol. 2010; 115:795-803.

21. Andersson KE. Prospective pharmacologic therapies for overactive bladder. Ther Adv Urol. 2009; 1:71-83.

22. Nishimura $M$, Ohkawara $T$, Sato $H$, et al. Pumpkin seed oil extracted from cucurbita maxima improves urinary disorders in human overactive bladder. J Tradit Complement Med. 2014; 4:72-4. 
23. Damiano $R$, Cai $T$, Fornara $P$, et al. The role of cucurbita pepo in the management of patients affected by lower urinary tract symptoms due to benign prostatic hyperplasia: a narrative review. Arch Ital Urol Androl. 2016; 88:136-143.

24. Kirino A, Takasuka Y, Nishi A, et al. Analysis and functionality of major polyphenolic components of Polygonum cuspidatum (itadori). J Nutr Sci Vitaminol. (Tokyo). 2012; 58:278-286.

25. Cruz F, Dinis P. Resiniferatoxin and botulinum toxin type A for treatment of lower urinary tract symptoms. Neurol Urodin. 2007; 26:920-927.

26. Apostolidis A, Gonzales GE, Fowler CJ. Effect of intravescical resiniferatoxin (RTX) on lower urinary tract symptoms, urodynam- ic parameters, and quality of life of patients with urodynamic increased bladder sensation. Eur Urol. 2006; 50:1299-1305.

27. Foster HE, Lake AG. Use of vanilloids in urologic disorders. Prog Drug Res. 2014; 68:307-317.

28. Fuentes F, Velasco DJ, Recuenco P. Metabolic role of glutamine and its importance in nutritional therapy Nutr Hosp. 1996; $11: 215-225$.

29. Vermeulen MA, Van De Poll MC, Ligthart-Melis GC, et al. Specific amino acids in the critically ill patient-exogenous glutamine/arginine: a common denominator?. Crit Care Med. 2007; 35 (9 suppl):S568-576.

30. Campos FG, Waitzberg DL, Logulo AF, et al. The role of glutamine in nutrition in clinical practice. Arg Gastroenterol. 1996; 33:86-92.

\section{Correspondence}

Carlo Vecchioli-Scaldazza, MD

cascave@alice.it

Uroginecology Unit, ASUR no 2 Jesi (AN)

Corso Cavour 66 - 62100 Macerata, Italy

Carolina Morosetti, MD

cmorose@libero.it

Clinical Laboratory Department, ASUR n ${ }^{\circ} 2$ Jesi (AN)

Via Maiolati 1 - 60035 Jesi (AN), Italy

Serena Maruccia, MD

info@serenamaruccia.it

Stefano Casellato, MD

stcasellato@gmail.com

Functional Urology Unit, Zucchi Clinical Institutes, Monza

Via Bartolomeo Zucchi, 24 - 20052 Monza, Italy

Wilma Rociola, MD

wilmarociola@virgilio.it

Urology Unit, ASL1, Umbria

Via Luigi Angelini 10 - 06012 Città di Castello (PG), Italy

Ester Illiano, MD

ester.illiano@inwind.it

Department of Surgical and Biomedical Sciences, Urology

and Andrology Clinic, University of Perugia

Piazzale Gambuli 1 - 06125 Perugia, Italy

Francesco Garofalo, MD

fgarofalo3@alice.it

Urology Division, Villa Maria Hospital, Rimini

Viale Giacomo Matteotti 24 - 47921 Rimini, Italy 